\title{
DESFOLHAÇÃO DE PERFILHOS EM PASTO DE CAPIM-BRAQUIÁRIA SOB LOTAÇÃO CONTÍNUA
}

\author{
Manoel Eduardo Rozalino Santos ${ }^{1}$, Dilermando Miranda da Fonseca ${ }^{2}$, Virgilio Mesquita Gomes ${ }^{3}$, \\ Marina Reis Sant’Anna e Castro ${ }^{4}$, Victor Valério de Carvalho ${ }^{4}$
}

\begin{abstract}
1 - Professor de Forragicultura e Pastagens - UFU - m_rozalino@yahoo.com.br
2 - Professor do Departamento de Zootecnia da Universidade Federal de Viçosa

3 - Doutorando do Departamento de Zootecnia da Universidade Federal de Viçosa

4 - Graduandos do Departamento de Zootecnia da Universidade Federal de Viçosa
\end{abstract}

\section{RESUMO}

Este trabalho foi desenvolvido para avaliar o número de perfilhos com níveis de desfolhação variáveis e suas características no pasto de Brachiaria decumbens cv. Basilisk. Os tratamentos foram locais do pasto (subpastejado, com pastejo adequado e sobrepastejado) e categorias de perfilhos (sem desfolhação, com desfolhação e sem o meristema apical). $\mathrm{O}$ delineamento foi em blocos ao acaso com três repetições. O pasto de $B$. decumbens foi manejado sob lotação contínua com bovinos, mantendo-se a altura média do pasto em $25 \mathrm{~cm}$. $\mathrm{O}$ número de perfilhos com desfolhação foi maior (1.333 perfilhos $/ \mathrm{m}^{2}$ ) no local sobrepastejado em comparação aos locais com pastejo adequado e subpastejado. Padrão de resposta inverso foi observado para os perfilhos sem desfolhação. Já o número de perfilhos sem o meristema apical foi maior no local com pastejo adequado (395 perfilhos $/ \mathrm{m}^{2}$ ). O perfilho sem desfolhação apresentou menor comprimento do pseudocolmo $(10,3 \mathrm{~cm})$ e menor número de folha morta $(0,22)$ quando comparado às demais categorias. O comprimento da lâmina foliar não diferiu entre as categorias de perfilhos avaliadas. $\mathrm{O}$ número de folhas pastejada foi menor no perfilho sem o meristema apical em relação aos perfilhos com e sem desfolhação. Observou-se menor área foliar nos perfilhos que tiveram o meristema apical removido. O perfilho sem o meristema apical apresentou menor percentual de lâmina foliar viva (LFV), maiores percentuais de colmo vivo (CV) e lâmina foliar morta, bem como inferior relação $\mathrm{LFV} / \mathrm{CV}$ e peso em relação aos perfilhos sem e com desfolhação. Estes últimos não diferiram entre si quanto à composição morfológica. Existe variabilidade espacial da vegetação e diversidade de perfilhos com níveis variáveis de desfolhação em pasto de $B$. decumbens cv. Basilisk sob lotação contínua.

PALAVRAS-CHAVES: Brachiaria decumbens; composição morfológica; número de perfilho; pastejo; variabilidade espacial da vegetação.

\section{TILLER DEFOLIATION ON SIGNAL GRASS PASTURES UNDER CONTINUOUS STOCKING}

The objective of this study was to evaluate the number of tillers with different levels of defoliation and their characteristics on the Brachiaria decumbens cv. Basilisk pasture. Three different areas on the pasture 
(undergrazed, with proper grazing and overgrazed) and three tiller categories (without defoliation, with defoliation and without shoot apical meristem) were evaluated. Randomized block design with three repetitions was used. The $B$. decumbens pasture was managed under the continuous stocking system with cattle, and the grass height was kept at about $25 \mathrm{~cm}$. The number of tillers showing defoliation was higher $(1,333$ tillers $/ \mathrm{m}^{2}$ ) for the overgrazed area compared to the area with proper grazing and the undergrazed area. Inverse response pattern was observed for the tillers without defoliation. On the other hand, the number of tillers without the shoot apical meristem was higher in the areas with proper grazing (395 tillers $/ \mathrm{m}^{2}$ ). Tillers without defoliation showed a lower pseudoculm length $(10.3 \mathrm{~cm})$ and a smaller number of dead leaves (0.22) when compared to the other categories. The length of the leaf blade did not change for the tiller categories evaluated. The number of grazed leaves was lower for tillers without the shoot apical meristem in relation to the ones showing or not defoliation. Lower leaf area for the tillers that had the shoot apical meristem removed was observed. Tillers without the shoot apical meristem showed a lower percentage of green leaf blade (GLB), higher percentages of both live culm (LC) and dead leaf blade (DLB) as well as a lower relation of the GLB/LC and weight comparing to the tillers showing or not defoliation. Those last ones did not differ regarding their morphological composition. There is indeed spatial variability of the vegetation and tiller diversity with varying levels of defoliation on Brachiaria decumbens cv. Basilisk pastures under continuous grazing.

KEYWORDS: Brachiaria decumbens; grazing; morphological composition; number of tillers; spatial variability of the vegetation.

\section{INTRODUÇÃO}

Atualmente, tem-se recomendado, como critério de manejo do pastejo, que as gramíneas tropicais sejam manejadas sob lotação contínua com taxa de lotação variável a fim de se manter o pasto em determinada altura e/ou em faixas de alturas adequadas. Essas alturas dos pastos visam garantir altas produções de forragem e, concomitantemente, bons níveis de produtividade animal (CARNEVALLI et al., 2001). Nesse sentido, o manejo do pastejo recomendável para a Brachiaria decumbens cv. Basilisk consiste na manutenção do pasto com altura média de 20 a $30 \mathrm{~cm}$ sob lotação contínua (SANTOS et al., 2011).

Mesmo nos pastos manejados com critério de manutenção de sua altura média fixa, é comum a ocorrência de variabilidade espacial da vegetação. Isso faz com que, em uma mesma pastagem, existam locais onde as plantas forrageiras possuem características diferenciadas, o que resulta na complexidade e diversidade de estruturas existentes no mesmo pasto.

Dentre as causas dessa heterogeneidade da vegetação no pasto, destaca-se o pastejo desuniforme dos ruminantes. Em verdade, em uma pastagem, existem locais com frequências e intensidades de pastejo variáveis (SANTOS et al., 2010a), o que resulta em locais com sobrepastejo ou subpastejo, mesmo quando se adota o critério de manejo do pastejo adequado.

O pastejo representa um estresse para as plantas, cuja magnitude depende da intensidade da desfolhação, que reduz a intercepção de luz e, também, a fotossíntese líquida do dossel, bem como a quantidade de compostos orgânicos de reserva e o crescimento de raízes (DAVIDSON \& MILTHORPE, 1966).

Nesse contexto, uma das formas de compreender as mudanças na estrutura do pasto ocasionadas pelo pastejo dos ruminantes consiste na caracterização de perfilhos individuais no pasto. Esses estudos reducionistas são necessários para uma pesquisa mais analítica e explicativa do ecossistema pastagem (SBRISSIA \& DA SILVA, 2008). Desse modo, a determinação do número de perfilhos no pasto, a sua classificação quanto ao nível de desfolhação, assim como a sua caracterização morfológica é relevante para compreender os efeitos do manejo do pastejo sobre a comunidade de plantas forrageiras.

Objetivou-se avaliar a densidade populacional de perfilhos com níveis de desfolhação variáveis e as características desses perfilhos individuais no pasto de Brachiaria decumbens cv. Basilisk manejado sob lotação contínua com bovinos e manutenção de sua altura média em $25 \mathrm{~cm}$.

\section{MATERIAL E MÉTODOS}

No período de outubro de 2008 a janeiro de 2009, o experimento foi conduzido no Setor Forragicultura do Departamento de Zootecnia da Universidade Federal de Viçosa, localizada em Viçosa-MG 
( $\left.20^{\circ} 45^{\prime} \mathrm{S} ; 42^{\circ} 51^{\prime} \mathrm{W} ; 651 \mathrm{~m}\right)$, numa área de pastagem de Brachiaria decumbens cv. Basilisk (Stapf.), estabelecida em 1997. A área experimental foi constituída de três piquetes de cerca de 0,30 ha, além de uma área reserva. O solo da área experimental é Latossolo Vermelho-Amarelo de textura argilosa. A análise química do solo, realizada no início do período experimental, na camada $0-20 \mathrm{~cm}$, apresentou os seguintes resultados: $\mathrm{pH}$ em $\mathrm{H}_{2} \mathrm{O}$ 4,79; $\mathrm{P}$ 1,5 (Mehlich-1) e K 86 mg/dm ${ }^{3} ; \mathrm{Ca}_{2}+1,46 ; \mathrm{Mg}_{2}+0,32 \mathrm{e}$ $\mathrm{Al}_{3+} 0,19 \mathrm{cmolc} / \mathrm{dm}^{3}(\mathrm{KCl} 1 \mathrm{~mol} / \mathrm{L})$. A área experimental foi adubada com $100 \mathrm{~kg} / \mathrm{ha}$ de $\mathrm{N}$ e $100 \mathrm{~kg} / \mathrm{ha}$ de $\mathrm{K}_{2} \mathrm{O}$ dividida em duas aplicações, uma em $11 / 11 / 2008$ e a outra em 15/12/2008, usando o formulado 20-05-20.

Os dados climáticos durante o período de avaliação foram registrados em estação meteorológica distante da área experimental aproximadamente 500 m (Tabela 1).

Tabela 1 - Médias mensais da temperatura média diária, insolação, precipitação pluvial total e evaporação total durante o período de outubro de 2008 a janeiro de 2009

\begin{tabular}{ccccc}
\hline Més & $\begin{array}{c}\text { Temperatura } \\
\text { média do ar } \\
\left({ }^{\circ} \mathrm{C}\right)\end{array}$ & $\begin{array}{c}\text { Insolação } \\
\text { (hora/dia) }\end{array}$ & $\begin{array}{c}\text { Precipitação } \\
\text { pluvial (mm) }\end{array}$ & $\begin{array}{c}\text { Evaporação } \\
(\mathrm{mm})\end{array}$ \\
\hline Outubro & 21,6 & 5,6 & 41,4 & 89 \\
Novembro & 28 & 3,7 & 223,8 & 65,8 \\
Dezembro & 21,3 & 11,1 & 626 & 270,8 \\
Janeiro & 22,5 & 13,2 & 250,7 & 137 \\
\hline
\end{tabular}

Desde outubro de 2008 até o término das avaliações em janeiro de 2009, os piquetes foram manejados sob lotação contínua com taxa de lotação variável de modo a manter a altura do pasto em aproximadamente $25 \mathrm{~cm}$. Para isso, a altura do pasto foi monitorada duas vezes por semana e foram utilizados bovinos machos, em recria, com peso médio de $200 \mathrm{~kg}$.

Os tratamentos consistiram de três locais no mesmo pasto e três categorias de perfilhos de capimbraquiária com distintos níveis de desfolhação. $\mathrm{O}$ delineamento foi em blocos ao acaso com três repetições. Os locais avaliados no pasto foram:

subpastejado: local onde o pasto estava com altura, no mínimo, duas vezes superior à sua altura média;

adequado: local em que o pasto estava com sua altura média, ou seja, aproximadamente $25 \mathrm{~cm}$;

sobrepastejado: local da pastagem em que o pasto possuía menos de $50 \%$ de sua altura média.

Com relação aos perfilhos, avaliaram-se as se- guintes categorias:

perfilho sem desfolhação: perfilhos em estádio vegetativo ou reprodutivo que não apresentavam sinais de desfolhação em uma ou mais lâminas foliares e que possuíam o meristema apical;

perfilho com desfolhação: perfilhos em estádio vegetativo ou reprodutivo que apresentavam desfolhação parcial ou total em uma ou mais lâminas foliares, porém possuíam o meristema apical;

perfilho sem o meristema apical: perfilhos em estádio vegetativo ou reprodutivo que não apresentavam o meristema apical devido a sua remoção pelo pastejo dos bovinos.

A medição da altura do pasto foi realizada com régua graduada ao longo de um caminhamento em zigue-zague pelos piquetes, mensurando-se 50 pontos por unidade experimental.

Para determinação da densidade populacional de perfilhos, foram colhidas nove amostras por piquete, sendo três amostras oriundas de cada local do pasto avaliado (subpastejo, adequado e sobrepastejo), com corte no nível do solo de todos os perfilhos contidos no interior de um quadrado de $0,25 \mathrm{~m}$ de lado. Esses perfilhos foram acondicionados em sacos plásticos identificados e, em seguida, levados para o laboratório, onde foram quantificados e classificados em perfilho sem desfolhação, perfilho com desfolhação e perfilho sem meristema apical.

Para mensuração das características estruturais, foram escolhidos aleatoriamente 10 perfilhos de cada categoria (sem desfolhação, com desfolhação e sem meristema apical) em locais do mesmo pasto que representavam sua condição média $(25 \mathrm{~cm}$ de altura). Em cada perfilho, foram medidos os comprimentos do pseudocolmo e de suas lâminas foliares completamente expandidas com auxílio de uma régua graduada. Além disso, foram quantificados os números de folhas vivas, com desfolhação e mortas de cada categoria de perfilhos. Com esses dados, obtiveram-se as seguintes variáveis:

número de folhas pastejadas: número médio de folhas por perfilho com remoção parcial ou total da lâmina foliar;

número de folhas vivas: número médio de folhas por perfilho completamente expandidas, incluindo as folhas pastejadas;

número de folhas mortas: número médio de folhas por perfilho com mais de $50 \%$ da lâmina foliar senescente;

comprimento da lâmina foliar: comprimento médio da lâmina foliar inserida na região interme- 
diária do perfilho;

comprimento do pseudocolmo: comprimento médio dos pseudocolmos.

Em cada piquete, também foram colhidas três amostras, constituídas de 30 perfilhos, referentes à cada categoria de perfilho avaliada. Os perfilhos foram cortados rente ao solo e em locais do piquete que representavam a condição média do pasto $(25$ $\mathrm{cm}$ de altura). Esses perfilhos foram identificados e levados para o laboratório, onde tiveram seus componentes morfológicos (lâmina foliar viva, colmo vivo e lâmina foliar morta) separados manualmente. As lâminas foliares vivas foram levadas para o medidor de área a fim de determinar sua área foliar e, depois, todos os componentes morfológicos foram colocados em sacos de papel identificados e levados à estufa de ventilação forçada, por 72 horas. Posteriormente, as amostras foram pesadas e, com esses dados, calculou-se o percentual de lâmina foliar viva, colmo vivo e lâmina foliar morta, assim como a área foliar por perfilho, o peso unitário do perfilho e a relação, em massa, entre a lâmina foliar viva e o colmo vivo.

As análises dos dados experimentais foram feitas de forma separada para os locais do pasto e as categorias de perfilhos. Foi realizada análise de variância e, posteriormente, compararam-se, de maneira separada, os locais do pasto e as categorias de perfilhos pelo teste de Tukey. Também foi gerado um gráfico de frequência relativa, para melhor visualização da variação espacial da altura do pasto. Todas as análises estatísticas foram realizadas em nível de significância de até $5 \%$ de probabilidade de ocorrência do erro tipo I.

\section{RESULTADOS E DISCUSSÃO}

O pasto de capim-braquiária manejado sob lotação contínua possuiu variabilidade espacial da vegetação, caracterizada por heterogeneidade nos valores de altura do pasto (Figura 1). Cerca de 30\% das plantas no pasto de capim-braquiária apresentou altura próxima $(22,5$ a $27,5 \mathrm{~cm})$ do critério de manejo do pastejo adotado, que foi a manutenção do pasto em $25 \mathrm{~cm}$ de altura média. Entretanto, aproximadamente $29 \%$ e $37 \%$ das plantas possuíram alturas mais baixas $(12,6$ a $22,4 \mathrm{~cm})$ e mais altas $(27,6$ a $49,9 \mathrm{~cm})$, respectivamente, do que a altura média em que o pasto foi mantido. Adicionalmente, ocorreram alguns locais na pastagem com altura extremamente baixa $(3,3 \%$ das plantas com até 12,5 $\mathrm{cm})$ e com altura muito elevada $(0,5 \%$ de plantas acima $50 \mathrm{~cm}$ ) (Figura 1). Realmente, a vegetação existente numa pastagem é, por natureza, espacialmente heterogênea, pois existe grande amplitude de valores no tocante às características descritoras da condição do pasto (BARTHRAM et al., 2005).

Os locais com alturas muito reduzida ou muito elevada foram denominados, neste trabalho, de sobrepastejado e subpastejado, respectivamente, porque possivelmente ficaram submetidos à intensidade e frequência de pastejo extremas. Em verdade, em pastagens é comum a existência de locais com padrões de desfolhação distintos, devido, dentre vários fatores, à seletividade de pastejo pelo animal (SANTOS et al., 2010b).

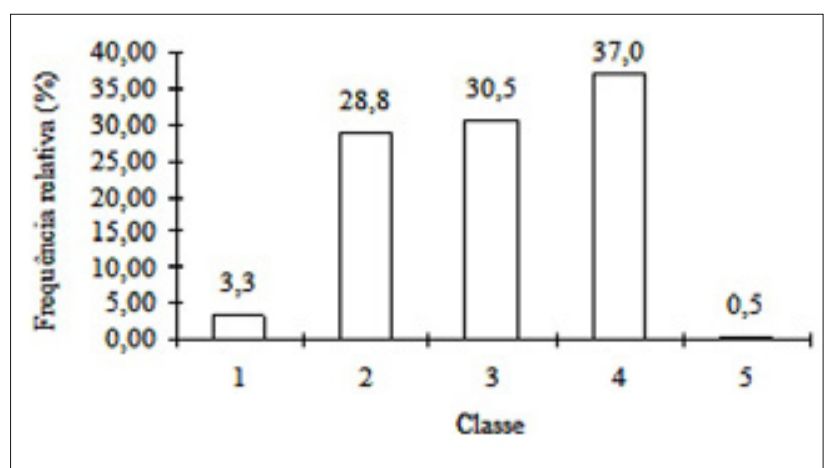

Figura 1 - Frequência relativa (\%) da altura do pasto de capim-braquiária manejado sob lotação contínua, com bovinos, durante o verão.

*Classes de altura do pasto: $1=$ até $12,5 \mathrm{~cm} ; 2=$ de 12,6 a 22,4 $\mathrm{cm} ; 3=$ de 22,5 a $27,5 \mathrm{~cm} ; 4=$ de 27,6 a $49,9 \mathrm{~cm} ; 5=$ acima de $50,0 \mathrm{~cm}$.

Vale salientar que o conceito de condição de pastejo adotado neste trabalho esteve relacionado com a condição pontual e/ou instantânea da forrageira em relação à condição média em que o pasto, como um todo, foi manejado. Nesse enfoque, os locais do pasto onde as plantas estavam com altura muito discrepante em relação à média do pasto foram considerados como condições de pastejo inadequado (sobrepastejo ou subpastejo). Já aqueles locais em que o pasto de capim-braquiária estava com aproximadamente $25 \mathrm{~cm}$ de altura foram considerados como situações de pastejo adequado. De fato, SANTOS et al. (2011) recomendam o manejo do pasto de $B$. decumbens, sob lotação contínua, dentro da faixa de altura entre 20 a $30 \mathrm{~cm}$.

Nesse contexto, são as características descritoras da forrageira, tal como sua altura, que foram avaliadas para discernir se o ambiente no qual a 
mesma está inserida correspondeu à situação de pastejo compatível com sua capacidade de tolerância à desfolhação. Realmente, acredita-se que, para cada forrageira, exista uma amplitude de condições de pasto específica em que sua resposta agronômica é máxima e/ou próxima da máxima e varia pouco (CARNEVALLI et al., 2001). Essas amplitudes de condição de pasto precisam ser conhecidas e respeitadas para que a pastagem não degrade devido ao sobrepastejo, ou para evitar a perda excessiva de forragem em decorrência do subpastejo. Esta conotação de adequabilidade da condição de pastejo é distinta daquela correntemente empregada, em que a condição de pastejo ótima é tida como aquela em que se tem um equilíbrio entre desempenho por animal e produção por unidade de área, de tal modo que resulte em maior produção por área (GOMIDE et al., 2001).

Com relação à classificação e quantificação dos perfilhos de capim-braquiária quanto ao nível de desfolhação, constatou-se que a densidade populacional de perfilhos com desfolhação foi maior $(\mathrm{P}<0,05)$ no local sobrepastejado em comparação aos locais com pastejo adequado e subpastejado. Padrão de resposta inverso foi observado para a categoria de perfilhos sem desfolhação (Figura 2). Esses resultados eram esperados porque nos locais do pasto com maior frequência e intensidade, como naqueles sobrepastejado, é natural que os perfilhos individuais sejam mais desfolhados e, adicionalmente, ocorra menor número de perfilhos sem desfolhação.

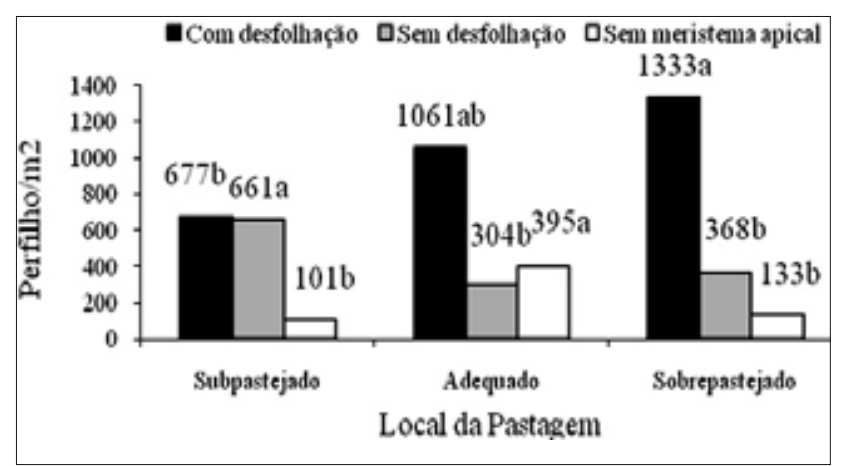

Figura 2 - Número de perfilhos com desfolhação, sem desfolhação e sem meristema apical em locais da pastagem de capim-braquiária manejada sob lotação contínua; Para cada categoria de perfilho, médias seguidas por letras distintas diferem pelo teste de Tukey $(\mathrm{P}<0,05)$.
Vale salientar que grande parte dos perfilhos sem desfolhação correspondeu aos perfilhos mais jovens no pasto que, por terem menor tamanho, não foram pastejados pelos bovinos. A maior densidade populacional desses perfilhos ocorreu no local subpastejado porque, nessa condição, os perfilhos de menor comprimento foram sobrepostos, no sentido vertical do pasto, pelos de maior tamanho, o que fez com que os bovinos pastejassem, primeira e preferencialmente, os perfilhos mais compridos, preservando da desfolhação os perfilhos menores.

$\mathrm{O}$ número de perfilhos sem o meristema apical foi maior $(\mathrm{P}<0,05)$ no local com pastejo adequado (Figura 2), o que indica que, nos locais em que as plantas estavam com $25 \mathrm{~cm}$ de altura, maior número de perfilhos foi desfolhado mais intensamente. De fato, a desfolhação mais intensa pode resultar na eliminação do meristema apical dos perfilhos (SANTOS et al., 2010b). Esse resultado seria esperado para o local com sobrepastejo, o que não ocorreu. Na condição de sobrepastejo, a despeito do elevado número de perfilhos com desfolhação (Figura 2), poucos perfilhos tiveram o meristema apical eliminado devido, possivelmente, aos mecanismos de adaptação do capim-braquiária ao sobrepastejo, que conferiram mudanças na sua morfologia. Essas adaptações morfológicas foram caracterizadas por modificações na forma de crescimento do capimbraquiária, que passou a ser mais prostrada, e também no tamanho dos perfilhos, que passou a ser menor. Essas mudanças na morfologia do capim-braquiária conferiram à planta menor possibilidade de desfolhação intensa, constituindo mecanismo de adaptação ao pastejo denominado de plasticidade fenotípica (SBRISSIA \& DA SILVA, 2008). Com desfolhação menos intensa, houve pouca eliminação do meristema apical dos perfilhos (Figura 2).

Já nos locais com subpastejo também houve menor $(\mathrm{P}<0,05)$ densidade populacional de perfilhos sem o meristema apical (Figura 2), porque provavelmente desfolhações menos intensas e, ou, frequentes ocorreram nesse local do pasto, fato comum em situações de pastejo leniente, em que os bovinos consomem, preferencialmente, as partes mais nutritivas da gramínea.

É relevante sublinhar que, no pasto de capimbraquiária manejado sob lotação contínua, houve pouca participação de perfilhos sem o meristema apical (Figura 2). Nos locais do pasto com subpaste- 
jo, pastejo adequado e sobrepastejo foram observados $7 \%, 23 \%$ e $7 \%$, de perfilhos sem o meristema apical, respectivamente. Os perfilhos sem desfolhação também tiveram pouca participação relativa nos locais do pasto com pastejo adequado (17\%) e com sobrepastejo $(20 \%)$, porém sua participação foi alta no local do pasto com subpastejo (46\%). De outro modo, os perfilhos desfolhados tiveram participação majoritária nos pastos de capim-braquiária, especialmente naqueles locais do pasto com pastejo adequado $(60 \%)$ e sobrepastejo $(73 \%)$.

A ocorrência de perfilhos com diferentes níveis de desfolhação no mesmo pasto de capim-braquiária pode ser benéfica para a pastagem. Nesse sentido, é possível, por exemplo, que, em uma mesma planta, os perfilhos sem desfolhação, que possuem rebrotação mais vigorosa devido ao seu alongamento foliar ocorrer a partir do meristema apical, compensem a menor taxa de rebrotação daqueles perfilhos sem meristema apical, que terão que recuperar sua área foliar via desenvolvimento de novas gemas axilares e, ou, basais. Isso permite que a interceptação de luz e o crescimento do pasto sejam otimizados.

Além de avaliar a densidade populacional das categorias de perfilhos nos distintos locais do pasto de capim-braquiária, também é importante caracterizar os perfilhos com níveis de desfolhação variáveis (Tabela 2). Nesse sentido, constatou-se que o perfilho sem desfolhação apresentou menor $(\mathrm{P}<0,05)$ comprimento do pseudocolmo quando comparado às demais categorias. Esse resultado se deve ao fato de que os perfilhos sem desfolhação corresponderam aos perfilhos mais jovens e, portanto de menor tamanho, existentes no pasto de capim-braquiária. Ao contrário, perfilhos com desfolhação e sem o meristema apical, provavelmente, apresentavam maior estádio de desenvolvimento, razão do seu pseudocolmo mais comprido (Tabela 2).

No tocante ao perfilho sem meristema apical, seu comprimento de pseudocolmo foi semelhante $(\mathrm{P}>0,05)$ ao do perfilho com desfolhação, porém maior $(\mathrm{P}<0,05)$ do que o do perfilho sem desfolhação (Tabela 2). Como perfilhos mais velhos possuem, em geral, o pseudocolmo mais comprido (SANTOS et al., 2009), infere-se que o perfilho sem meristema apical possuía maior estádio de desenvolvimento. Em verdade, mesmo considerando que seu ápice foi removido pelo pastejo dos bovinos, ainda assim, o perfilho sem meristema apical apresentou o pseudocolmo mais comprido. Esse argumento de que o perfilho sem meristema apical estava com maior estádio de desenvolvimento encontra respaldo no seu maior $(\mathrm{P}<0,05)$ número de folhas mortas, que é característico de perfilhos mais velhos (SANTOS et al., 2009).

O menor estádio de desenvolvimento do perfilho sem desfolhação também é a razão do seu menor $(\mathrm{P}<0,05)$ número de folhas mortas (Tabela 2$)$. De fato, em perfilhos mais jovens a senescência foliar tende a ser menos acentuada (CARNEVALLI et al., 2006; BARBOSA et al., 2007), porque suas lâminas foliares ainda não ultrapassaram a duração de vida.

Tabela 2 - Características estruturais de perfilhos de Brachiaria decumbens cv. Basilisk sob lotação contínua em função do nível de desfolhação

\begin{tabular}{lcccc}
\hline Característica & \multicolumn{3}{c}{ Perfilho } & CV (\%) \\
\hline & \multirow{2}{*}{ Sem desfollhação } & Com desfolhação & Sem meristema apical \\
\hline Comprimento do pseudocolmo $(\mathrm{cm})$ & $10,30 \mathrm{~b}$ & $17,32 \mathrm{a}$ & $19,74 \mathrm{a}$ & 6,04 \\
Comprimento da lâmina foliar $(\mathrm{cm})$ & $6,95 \mathrm{a}$ & $8,88 \mathrm{a}$ & $7,57 \mathrm{a}$ & 14,2 \\
Número de folha viva & $3,64 \mathrm{~b}$ & $4,53 \mathrm{a}$ & $1,77 \mathrm{c}$ & 9,07 \\
Número de follha pastejada & $0,00 \mathrm{c}$ & $2,99 \mathrm{a}$ & $1,62 \mathrm{~b}$ & 22,3 \\
Número de folha morta & $0,22 \mathrm{c}$ & $1,32 \mathrm{~b}$ & $2,43 \mathrm{a}$ & 8,09 \\
\hline
\end{tabular}

${ }^{1}$ Coeficiente de variação; médias seguidas por mesma letra na linha não diferem pelo teste de Tukey $(\mathrm{P}>0,05)$.

O comprimento da lâmina foliar não diferiu $(\mathrm{P}>0,05)$ entre as categorias de perfilhos avaliadas (Tabela 2), o que pode ter sido resultado do critério de amostragem utilizado neste trabalho, em que os perfilhos sempre foram colhidos no local do pasto com mesma altura de $25 \mathrm{~cm}$.
Com a remoção do ápice do perfilho, que resultou na eliminação de seu meristema apical, é possível que parte das folhas vivas mais jovens e de maior nível de inserção tenha sido consumida pelos bovinos, o que explicaria o seu menor $(\mathrm{P}<0,05)$ nú- 
mero de folhas vivas em relação aos demais perfilhos avaliados (Tabela 2). Adicionalmente, essa remoção do ápice do perfilho fez com que apenas as folhas mais velhas e de menor nível de inserção remanescessem. Como essas folhas estão localizadas na região basal do pasto, é natural que tenham menor probabilidade de desfolhação, na medida em que os bovinos pastejam preferencialmente as folhas presentes no extrato superior do pasto. Realmente, o número de folhas pastejada foi menor $(\mathrm{P}<0,05)$ no perfilho sem o meristema apical em relação aos perfilhos com e sem desfolhação (Tabela 2).

Não houve diferença $(\mathrm{P}>0,05)$ entre as áreas foliares dos perfilhos sem e com desfolhação; entretanto, observou-se $(\mathrm{P}<0,05)$ menor área foliar nos perfilhos que tiveram o meristema apical removido (Figura 3), de tal modo que ocorreu diminuição de $77 \%$ na área foliar dos perfilhos sem meristema apical, em comparação aos sem desfolhação.

Quando a intensidade de desfolhação do perfilho é alta, há tendência de eliminação do meristema apical. Nesse sentido, considerando-se que o capim-braquiária é uma forrageira que, em geral, não apresenta elevação precoce do meristema apical, infere-se que a remoção do meristema dos perfilhos foi acompanhada de acentuada intensidade de pastejo, promovendo alta perda da área foliar por perfilho (Figura 3). A área foliar é de extrema importância para manutenção da planta forrageira no ecossistema, já que a maior taxa de fotossíntese ocorre nas lâminas foliares, especialmente naquelas mais jovens (PARSONS et al., 1983). Dessa forma, a remoção foliar reduz a capacidade da planta em gerar fotoassimilados, o que, consequentemente, atrasa a rebrotação do perfilho após o pastejo (TAIZ \& ZEIGER, 2006).

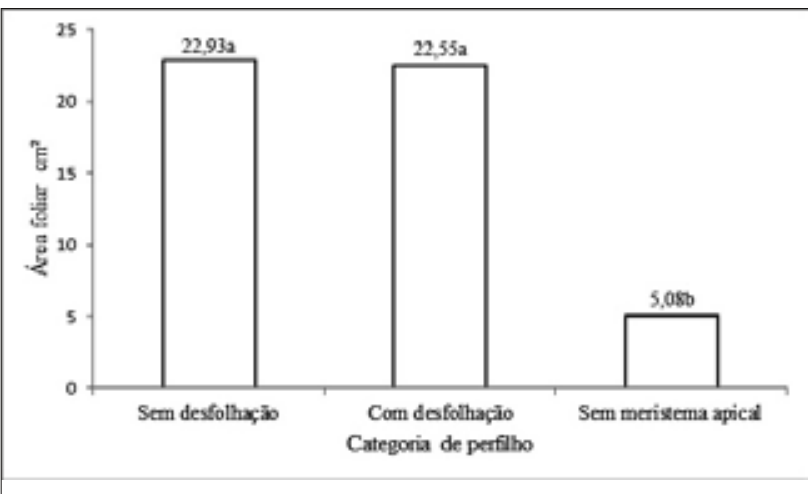

Figura 3- Área foliar do perfilho sem desfolhação, com desfolhação e sem meristema apical em pasto de capim-braquiária manejado sob lotação contínua; médias seguidas por letras distintas diferem pelo teste de Tukey $(\mathrm{P}<0,05)$.

Poder-se-ia esperar que o perfilho sem desfolhação apresentasse maior área foliar do que as demais categorias de perfilhos estudadas; contudo, conforme discutido, o perfilho sem desfolhação possuía, geralmente, menor estádio de desenvolvimento e, com efeito, sua área foliar ainda estava em expansão. De fato, em perfilhos vegetativos, a área foliar é incrementada durante seu estádio de desenvolvimento (SANTOS et al., 2009). Isso justifica o fato do perfilho sem desfolhação ter apresentado área foliar semelhante à do perfilho com desfolhação (Figura 3).

Com relação à composição morfológica das categorias de perfilhos, o perfilho sem meristema apical apresentou menor $(\mathrm{P}<0,05)$ percentual de lâmina foliar viva $(\mathrm{LFV})$, maiores $(\mathrm{P}<0,05)$ percentuais de colmo vivo $(\mathrm{CV})$ e lâmina foliar morta, bem como inferior $(\mathrm{P}<0,05)$ relação $\mathrm{LFV} / \mathrm{CV}$ em relação aos perfilhos sem e com desfolhação. Estes últimos não diferiram $(\mathrm{P}>0,05)$ entre si quanto à composição morfológica (Tabela 3 ).

Tabela 3- Composição morfológica de perfilhos de Brachiaria decumbens cv. Basilisk sob lotação contínua em função do nível de desfolhação

\begin{tabular}{lcccc}
\hline \multicolumn{1}{c}{ Caracteristica } & \multicolumn{3}{c}{ Perfilho } & CV (\%) ${ }^{1}$ \\
\hline & Sem desfolhação & Com desfolhação & Sem meristema apical \\
\hline Lâmina foliar viva (\%) & $52,54 \mathrm{a}$ & $46,60 \mathrm{a}$ & $10,19 \mathrm{~b}$ & 6,71 \\
Colmo vivo (\%) & $44,03 \mathrm{~b}$ & $49,51 \mathrm{~b}$ & $70,30 \mathrm{a}$ & 6,79 \\
Lâmina foliar morta (\%) & $3,42 \mathrm{~b}$ & $3,89 \mathrm{~b}$ & $19,51 \mathrm{a}$ & 55,44 \\
LFV/CV2 & $1,19 \mathrm{a}$ & $0,94 \mathrm{a}$ & $0,15 \mathrm{~b}$ & 7,84 \\
\hline
\end{tabular}

${ }^{1}$ Coeficiente de variação; ${ }^{2}$ relação entre as massas de lâmina foliar viva e colmo vivo; médias seguidas por mesma letra na linha não diferem pelo teste de Tukey $(\mathrm{P}>0,05)$. 
Perfilhos sem meristema apical possuíram maiores participações de lâmina foliar morta e colmo vivo em decorrência da menor síntese de lâminas foliares vivas nesses perfilhos, já que parte de suas células meristemáticas foram removidas juntamente com o ápice dos perfilhos. Ademais, conforme discutido anteriormente, deduziu-se que os perfilhos sem meristema apical corresponderam às categorias com maior estádio de desenvolvimento e, por isso, eram esperados seus maiores percentuais de colmo vivo e lâmina foliar morta, bem como sua menor participação relativa de lâmina foliar viva e sua inferior relação LFV/CV (SANTOS et al., 2010c). Vale salientar que a composição morfológica do perfilho sem o meristema apical foi, em última instância, resultado do maior comprimento do seu pseudocolmo, menor número de folhas vivas e superior número de folhas mortas (Tabela 2).

Por sua vez, a melhor composição morfológica do perfilho sem desfolhação decorreu do seu menor estádio de desenvolvimento. De fato, vários trabalhos (SANTOS et al., 2009; SANTOS et al., 2010c) demonstram que, com o avanço da maturidade do perfilho, sua composição morfológica fica desfavorável em virtude do incremento da participação de componentes morfológicos de pior valor nutritivo, quais sejam, colmo e folha morta (SANTOS et al., 2010c).

Com relação ao peso dos perfilhos, observouse menor $(\mathrm{P}<0,05)$ valor para aqueles sem meristema apical, não havendo diferença $(\mathrm{P}>0,05)$ para perfilhos sem e com desfolhação (Figura 4). A despeito do maior comprimento do pseudocolmo (Tabela 2), perfilhos sem meristema apical possuem maior remoção de tecidos foliares e de parte do pseudocolmo, o que justifica seu menor peso. Vale sublinhar que a remoção do meristema apical pode estimular o perfilhamento lateral (TAIZ \& ZEIGER, 2006), e, com isso, o peso do perfilho tende a ser incrementado, porém esse fato não ocorreu no presente trabalho, o que pode ser atribuído à característica do capim-braquiária, que apresenta baixo número de perfilhos aéreos e, quando estes ocorrem, são de tamanho reduzido.

O pastejo total ou parcial das lâminas foliares dos perfilhos com desfolhação fez com que os mesmos possuíssem peso semelhante ao perfilho sem desfolhação (Figura 4), mesmo sendo estes últimos de menor estádio de desenvolvimento.

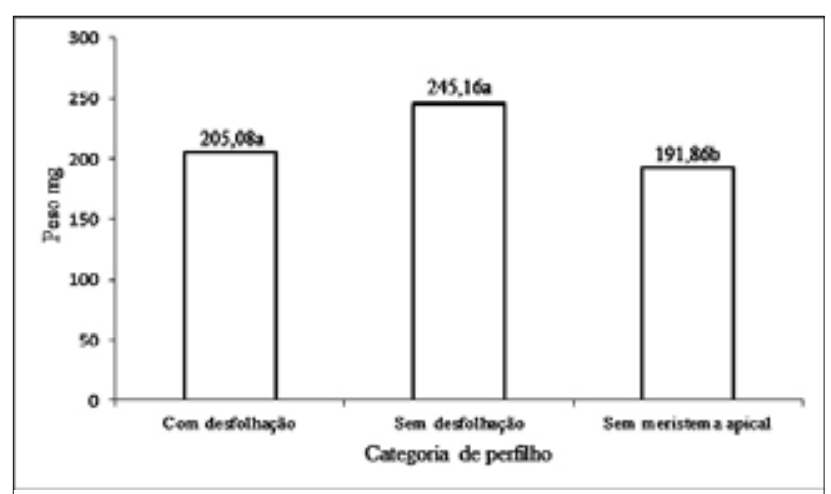

Figura 4 - Peso do perfilho sem desfolhação, com desfolhação e sem meristema apical no pasto de capim-braquiária manejado sob lotação contínua; médias seguidas por letras distintas diferem pelo teste de Tukey $(\mathrm{P}<0,05)$

Os dados apresentados neste trabalho permitem constatar que existe diversidade de estruturas no mesmo pasto de capim-braquiária manejado sob lotação contínua e com o critério de manutenção de sua altura média em $25 \mathrm{~cm}$. Essa assertiva é justificada pela existência de locais subpastejado, com pastejo adequado e com sobrepastejo na mesma pastagem (Figura 1) e tendo em vista que, em cada local avaliado, as densidades populacionais das categorias de perfilhos com níveis de desfolhação variáveis também foram diferentes (Figura 2).

Da mesma forma, é possível afirmar que no pasto de capim-braquiária manejado sob lotação contínua há diversidade de perfilhos com distintos níveis de desfolhação. Isso pode ter importância para a persistência do pasto na medida em que, numa mesma planta, perfilhos sem desfolhação podem auxiliar na rebrotação daqueles perfilhos com desfolhação ou sem o meristema apical (MARSHALL \& SAGAR, 1965), o que otimiza a formação da nova área foliar, premissa fundamental para a interceptação de luz e a ocorrência de fotossíntese no dossel (TAIZ \& ZEIGER, 2006).

\section{CONCLUSÕES}

Em pasto de Brachiaria decumbens cv. Basilisk sob lotação contínua existe variabilidade espacial da vegetação e diversidade de perfilhos com níveis variáveis de desfolhação. Nesse pasto, o local subpastejo possui maior número de perfilho sem desfolhação e o local sobrepastejo apresenta maior densidade populacional de perfilhos com desfolhação. 
O perfilho de $B$. decumbens sem o meristema apical possui maior comprimento do pseudocolmo e maior número de folha morta do que os perfilhos com e sem desfolhação, porém apresenta menor número de folha viva, inferior área foliar e menor peso.

Em pastagem de $B$. decumbens sob lotação contínua, perfilhos sem desfolhação possuem menor comprimento do pseudocolmo e reduzido número de folha morta.

\section{REFERÊNCIAS}

BARBOSA, R.A.; NASCIMENTO JÚNIOR, D.; EUCLIDES, V.B.P.; SILVA, S.C.; ZIMMER, A.H.; TORRES JÚNIOR, R.A.A. Capim-tanzânia submetido a combinações entre intensidade e frequência de pastejo. Pesquisa Agropecuária Brasileira, v.42, n.3, p.329340, 2007.

BARTHRAM, G. T.; DUFF, E. I.; ELSTON, D. A.; GRIFFITHS, J. H.; COMMON T. G.; MARRIOTT C. A. Frequency distributions of sward height under sheep grazing. Ltd. Grass and Forage Science, v.60, p.04-16, 2005 .

CARNEVALLI, R.A.; DA SILVA, S.C.; CARVALHO, C.A.B.; SBRISSIA, A.F.; FAGUNDES, J.L.; PINTO, L.F.M.; PEDREIRA, C.G.S. Desempenho de ovinos e respostas de pastagens de Coastcross (Cynodon spp.) submetidas a regimes de desfolha sob lotação contínua. Pesquisa Agropecuária Brasileira, v.36, n.6, p.919927, 2001

CARNEVALLI, R.A.; DA SILVA, S.C.; BUENO, A.A.O.; UEBELE, M.C.; BUENO, F.O.; HODGSON, G.N.; SILVA, G.N.; MORAES, J.P.G. Herbage production and grazing losses in Panicum maximum cv. Mombaça under four grazing managements. Tropical Grasslands, v.40, p.165-176, 2006.

DAVIDSON, J.L.; MILTHORPE, F.L. The effect of defoliation on the carbon balance in Dactylis glomerata. Annals of Botany, v.30, n.118, p.185-198, 1966.
GOMIDE, J.A.; WENDLING, I.J.; BRAS, S.P.; QUADROS, E.H. Consumo e produção de leite de vacas mestiças em pastagem de Brachiaria decumbens manejada sob duas ofertas diárias de forragem. Revista Brasileira de Zootecnia, v.30, n.4, p.1194-1199, 2001.

MARSHALL, C.; SAGAR, G.R. The influence of defoliation on the distribution of assimilates in Lolium multiflorum. Annals of Botany, v.29, n.115, p.365-372, 1965.

PARSONS, A.J.; LEAFE, E.L., COLLETT, B.; STILES, $\mathrm{W}$. The physiology of grass production under grazing. I Characteristics of leaf and canopy photosynthesis of continuously grazed swards. Journal of Applied Ecology, v.20, p. 117-126, 1983

SANTOS, M.E.R.; FONSECA, D.M.; BALBINO, E.M.; SILVA, S.P.; MONNERAT, J.P.I.S.; GOMES, V.M. Variabilidade espacial e temporal da vegetação em pastos de capimbraquiária diferidos. Revista Brasileira de Zootecnia, v.39, n.4, p.727-735, 2010a.

SANTOS, M.E.R.; FONSECA, D.M.; GOMES, V.M.; PIMENTEL, R.M.; SILVA, G.P.; SILVA, S.P. Caracterização de perfilhos de capim-braquiária em locais com três intensidades de pastejo. Revista Brasileira de Saúde e Produção Animal, v.11, n.4, p.961-975, 2010 b.

SANTOS, M.E.R.; FONSECA, D.M.; BALBINO, E.M.; SILVA, S.P.; MONNERAT, J.P.I.S.; GOMES, V.M. Características estruturais de perfilhos vegetativos e reprodutivos em pastos diferidos de capim-braquiária. Ciência Animal Brasileira, v.11, n.3, p.492-502, 2010c.

SANTOS, M.E.R.; FONSECA, D.M.; GOMES, V.M.; PIMENTEL, R.M.; ALBINO, R.L.; SILVA, S.P. Estádio de desenvolvimento e características morfológicas de lâminas foliares e de perfilhos de capim-braquiária sob lotação contínua. Boletim de Indústria Animal, v.66, n.2, p.95-105, 2009

SBRISSIA, A.F.; DA SILVA, S.C. Compensação tamanho:densidade populacional de perfilhos em pastos de capim-marandu. Revista Brasileira de Zootecnia, v.37, n.1, p.35-47, 2008.

TAIZ, L.; ZEIGER, E. Fisiologia Vegetal. Porto Alegre: Artmed, 3 ed., 2006. 719p. 